\title{
Evidence and assessment of parenchymal patterns of ultrasonography for breast cancer detection among Chinese women: a cross-sectional study
}

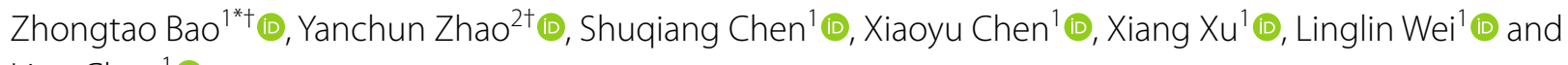
Ling Chen ${ }^{1}$ (1)

\begin{abstract}
Background: Screening of breast cancer in asymptomatic women is important to evaluate for early diagnosis. In China ultrasound is a more frequently used method than mammography for the detection of breast cancer. The objectives of the study were to provide evidence and assessment of parenchymal patterns of ultrasonography for breast cancer detection among Chinese women.

Methods: Breast ultrasound examinations including the parenchymatous pattern of cytopathological confirmed breast cancer $(n=541)$ and age-matched cytopathological not confirmed breast cancer $(n=849)$ women were retrospectively reviewed by seven sonographer physicians. According to compositions of ducts, the thickness of the breast, diameter of ducts, fat lobules, and fibro glandular tissues, the breast parenchymatous pattern was categorized into heterogeneous (high percentage of fatty tissues), ductal (the inner diameters of ducts $>50 \%$ of the thick mass of the breast), mixed (the inner diameters of ducts was $50 \%$ of the thick mass of the breast), and fibrous categories (a dense classification of the breast).
\end{abstract}

Results: Heterogeneous $(p<0.0001, \mathrm{OR}=3.972)$ and fibrous categories $(p<0.0001, \mathrm{OR}=2.702)$ were higher among women who have cytopathological confirmed breast cancer than those who have not cytopathological confirmed breast cancer. The heterogeneous category was high-risk ultrasonographic examination category followed by the fibrous category. Agreements between sonographer physicians for categories of ultrasonic examinations were fair to good (Cohen's $k=0.591)$.

Conclusions: Breast cancer risk in Chinese asymptomatic women differ according to the ultrasonographic breast parenchymal pattern.

Level of Evidence: III.

Technical efficacy stage: 2.

\footnotetext{
*Correspondence: BarbraHooperfek@yahoo.com

†Zhongtao Bao and Yanchun Zhao have contributed to this work equally.

1 Department of Ultrasound, First Affiliated Hospital of Fujian Medical

University, No 20 Cha zhong Road, Taijiang District, Fuzhou 350000, Fujian,

China

Full list of author information is available at the end of the article
}

(C) The Author(s) 2021. Open Access This article is licensed under a Creative Commons Attribution 4.0 International License, which permits use, sharing, adaptation, distribution and reproduction in any medium or format, as long as you give appropriate credit to the original author(s) and the source, provide a link to the Creative Commons licence, and indicate if changes were made. The images or other third party material in this article are included in the article's Creative Commons licence, unless indicated otherwise in a credit line to the material. If material is not included in the article's Creative Commons licence and your intended use is not permitted by statutory regulation or exceeds the permitted use, you will need to obtain permission directly from the copyright holder. To view a copy of this licence, visit http://creativecommons.org/licenses/by/4.0/. The Creative Commons Public Domain Dedication waiver (http://creativeco $\mathrm{mmons}$.org/publicdomain/zero/1.0/) applies to the data made available in this article, unless otherwise stated in a credit line to the data. 
Keywords: Breast cancer, Breast cancer risk, Breast density, Breast cancer screening, Breast parenchymatous tissue, Chinese women, Ultrasound

\section{Background}

Breast cancer is the most common in Chinese women [1, 2]. Screening of breast cancer in asymptomatic women is important to evaluate for the early diagnosis [3]. Considering various risks for breast cancer, various breast cancer assessment models are developed to identify the risk of breast cancer [1] but there is a lack of a consistent breast cancer assessment model for Chinese women [4]. A proper screening method of breast cancer for Chinese women is necessary [5].

Genetic and environmental factors affect breast parenchymatous tissue structure and there is a correlation between breast parenchymatous tissue structure and the risk of breast cancer in any individual woman [6]. Therefore, it is possible to predict the breast cancer risk of a healthy woman by imaging modalities like mammography and ultrasound.

Mammography is an established imaging method for breast cancer screening because it has accuracy but has low sensitivity [7]. This is because the mammary parenchyma of women is different due to different parameters [8]. Also, mammography is successful among Caucasian women [3]. However, Chinese women have comparatively smaller and dense breasts and have greater parenchymal density than Caucasian women [9]. Mammography has lower sensitivity for dense tissues of the breast [10] and ultrasound is a cost-effective and more sensitive imaging method for dense tissues of the breast [11]. Therefore, in China ultrasound is a more frequently used method than mammography for the detection of breast cancer [3]. The Chinese government is started breast cancer screening by ultrasound in rural areas [3].

The objectives of retrospective analysis of cross-sectional study were to provide evidence and assessment of breast parenchymal patterns of ultrasonography for breast cancer detection among Chinese women considering those of women with cytopathology confirmed breast cancer as a reference standard.

\section{Methods}

\section{Inclusion criteria}

Women who underwent ultrasound examinations for breast cancer screening were included in the analyses.

\section{Exclusion criteria}

Women who underwent breast cancer surgeries, estrogen replacement therapy, and have incomplete data in the institutional records were excluded from the study.

\section{Ultrasound examination}

In a lateral or supine position with raised arms, fully exposed breasts, and axillae conditions of women, ultrasound examinations were performed. EPIQ 5 (Koninklijke Philips N.V., Amsterdam, Netherlands), M8 (Mindray Medical International Limited, Nanshan, Shenzhen, China), and iU22 (Philips, Amsterdam, Netherlands) ultrasound devices were preferred to examine women. Linear array probes for $5-13 \mathrm{MHz}, 6.6-13 \mathrm{MHz}$, and 7.5-10 MHz respectively were used. All examinations were performed by seven sonographer physicians (minimum 3-years experiences of institutes). Multiangle and multi-plane ultrasound scans were performed for bilateral breasts and axillae. Two mutually orthogonal planes were used for confirmation of all lesions. The characteristics of the breast parenchyma and ultrasound images of all lesions were recorded. The images were taken at the same location in each breast.

\section{Breast biopsies}

Ultrasound-guided core biopsies were performed using an 18 G needle (BD Biosciences, Chicago, IL, USA) [12]. Core biopsies were performed by pathologists (minimum 3 -years of experience of institutes).

\section{Breast tissues histopathology}

Breast tissue histopathology was performed by pathologists (minimum 3-years of experience of institutes). The diagnosis of breast cancer was confirmed by breast tissue histopathology.

\section{Ultrasonographic classification}

The thickness of the breast, ducts, fat lobules, and fibro glandular tissues were examined by ultrasonography. According to compositions of ducts, the thickness of the breast, diameter of ducts, fat lobules, and fibro glandular tissues, the breast parenchymatous pattern was categorized into 4 types: heterogeneous category: the inner diameters of ducts were less than $50 \%$ of a thick mass of the breast, the hypo-echoic fatty mass of the breast, less dense iso-echoic fibro glandular tissue, and hypo-echoic ductal ingredients. Ductal category: the inner diameters of ducts was more than $50 \%$ of the thick mass of the breast, hypo-echoic ductal ingredients in the mesh structure. Mixed category: the inner diameters of ducts was $50 \%$ of the thick mass of the breast, iso-echoic fibro glandular tissue, and hypo-echoic ductal ingredients. Fibrous category: the inner diameters of ducts was less than $50 \%$ 
of the thick mass of the breast, dense iso-echoic fibro glandular tissue, and less hypo-echoic ductal ingredients [3]. The different breast parenchymatous pattern categories are presented in Fig. 1.

\section{Statistical analysis}

SPSS 26.0 IBM Corporation, Armonk, NY, USA was used for statistical analyses. One-way analysis of variance (ANOVA) was used for categorical data and the Fischer exact test or Chi-square test of Independence was used for continuous data. All results were considered significant if $p<0.05$, odds ratio (OR) with $95 \%$ of confidence interval $(\mathrm{Cl})$. Cohen's $k$ was evaluated for agreements among sonographer physicians. Values were $0 \leq k \geq 0.4$ : poor agreement, $0.41 \leq k \geq 0.75$ : fair to good agreement, $0.76 \leq k>1.0$ : excellent agreement, $k=1.0$ : perfect agreement [13].

\section{Results}

\section{Study population}

A total of 6,125 Chinese women have undergone ultrasound examinations at the First Affiliated Hospital of Fujian Medical University, Fuzhou, Fujian, China and the Fujian Provincial Hospital, Fuzhou, Fujian, China from 15 April 2015 to 13 May 2019. Three women underwent breast cancer surgeries, two women underwent estrogen
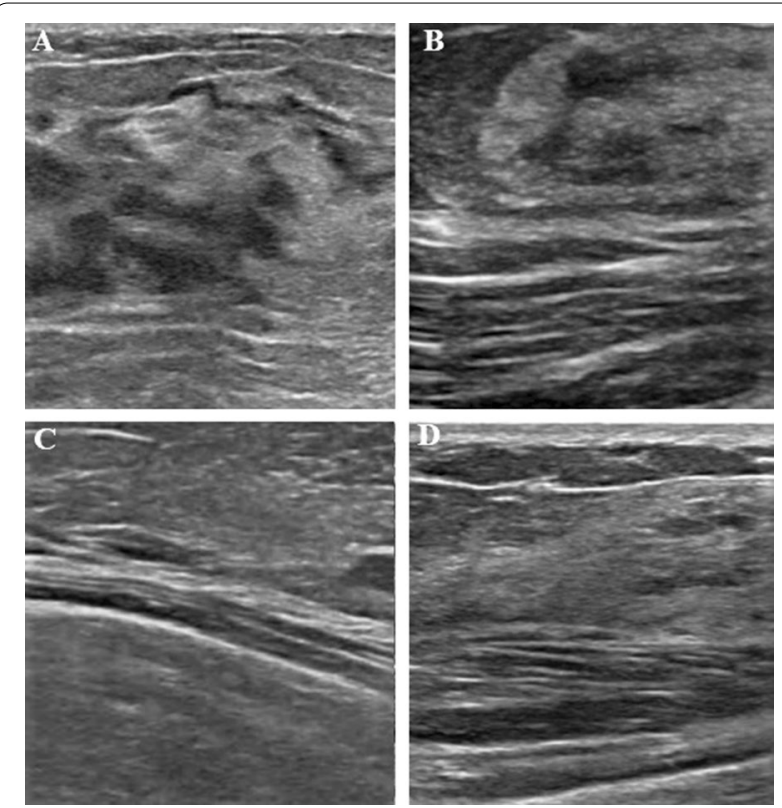

Fig. 1 Ultrasonographic classification. a heterogeneous category (high percentage of fatty tissues), $\mathbf{b}$ ductal category (the inner diameters of ducts $>50 \%$ of the thick mass of the breast), c Mixed category (the inner diameters of ducts was $50 \%$ of the thick mass of the breast), and $\mathbf{d}$ Fibrous category (a dense classification of the breast) replacement therapy, and five women have no complete data in the institutional records. Therefore, data of these women $(n=10)$ were excluded from the study. Among 6,115 women, 541 women had cytopathological confirmed breast cancer. From 5,574 cytopathological not confirmed breast cancer women, data of 849 agematched women were randomly selected for the study. The demographical, social, and clinical conditions of women are presented in Table 1. The flow diagram of the study is presented in Fig. 2.

\section{Ultrasound examination}

Heterogeneous and fibrous categories were higher among women who have cytopathological confirmed breast cancer than those who have not cytopathological confirmed breast cancer $(p<0.0001$ for both). However, mixed type and ductal categories were the same among women who have cytopathological confirmed breast cancer and those who have not cytopathological confirmed breast cancer. The breast parenchymatous pattern categories shown in ultrasound examinations are reported in Table 2. Heterogeneous and fibrous categories were high-risk ultrasonographic examination categories for breast cancer. The OR is highest for the heterogeneous category followed by the fibrous category.

\section{Agreements among sonographer physicians}

Agreements among sonographer physicians for categories of ultrasonic examinations were fair to good (Table 3).

\section{Discussion}

The current study reported that heterogeneous and fibrous categories were high-risk ultrasonographic examination categories for breast cancer. The results of the breast parenchymatous pattern categories of the current study were agreed with those of an available study [3], retrospective studies [14, 15], and case-control study [16]. The heterogeneous category in the current study was included a high percentage of fatty tissues. The higher amount of breast fatty tissue independent of the other risk factors is associated with the risk of breast cancer [16]. The fibrous category in the current study was included a dense classification of the breast. Atypical epithelial hyperplasia is associated with the risk of breast cancer [17]. The distribution of ultrasonographic parenchymatous patterns is different between women who have cytopathological confirmed breast cancer and those who have not cytopathological confirmed breast cancer.

The study reported fair to good agreements among sonographer physicians for categories of ultrasonic examinations. The results of agreements between sonographer physicians for categories of ultrasonic examinations were 
Table 1 The demographical, social, and clinical conditions of women who underwent ultrasound examination and selected for study

\begin{tabular}{|c|c|c|c|c|}
\hline \multicolumn{2}{|l|}{ Parameters } & \multirow{2}{*}{$\begin{array}{l}\text { Cytopathological did not confirm } \\
\text { breast cancer women } \\
849\end{array}$} & \multirow{2}{*}{$\begin{array}{l}\text { Cytopathological confirmed } \\
\text { breast cancer women } \\
541\end{array}$} & \multirow{2}{*}{$\begin{array}{l}\text { Comparisons } \\
p \text {-value }\end{array}$} \\
\hline Women & & & & \\
\hline \multirow[t]{3}{*}{ Age at examination (years) } & Minimumact & 27 & 25 & 0.221 \\
\hline & Maximum & 72 & 71 & \\
\hline & Mean \pm SD & $50.12 \pm 11.19$ & $49.48 \pm 15.14$ & \\
\hline \multirow[t]{4}{*}{ Ethnicity } & Han Chinese & 787 (92.88) & $506(93.8)$ & 0.915 \\
\hline & Mongolian & $52(6)$ & $29(5)$ & \\
\hline & Tibetan & $9(1)$ & $5(1)$ & \\
\hline & Uighur Muslim & $1(0.12)$ & $1(0.2)$ & \\
\hline \multirow[t]{2}{*}{ Menopausal status } & Premenopausal & $520(61)$ & $335(62)$ & 0.821 \\
\hline & Postmenopausal & $329(39)$ & $206(38)$ & \\
\hline \multirow[t]{2}{*}{ Body mass index $\left(\mathrm{kg} / \mathrm{m}^{2}\right)$} & $<25$ & $625(74)$ & $403(74)$ & 0.751 \\
\hline & $\geq 25$ & $224(26)$ & $138(26)$ & \\
\hline \multirow[t]{2}{*}{ Family history of breast cancer } & Yes & $48(6)$ & $32(6)$ & 0.906 \\
\hline & No & $801(94)$ & 509 (94) & \\
\hline
\end{tabular}

Categorial data are demonstrated as frequency (percentages) and continuous data are mean $\pm \mathrm{SD}$ (standard deviation)

One-way ANOVA for categorical data and Fischer exact test or Chi-square test of Independence for continuous data were performed for statistical analyses

All results were considered significant if the $p$-value less than 0.05

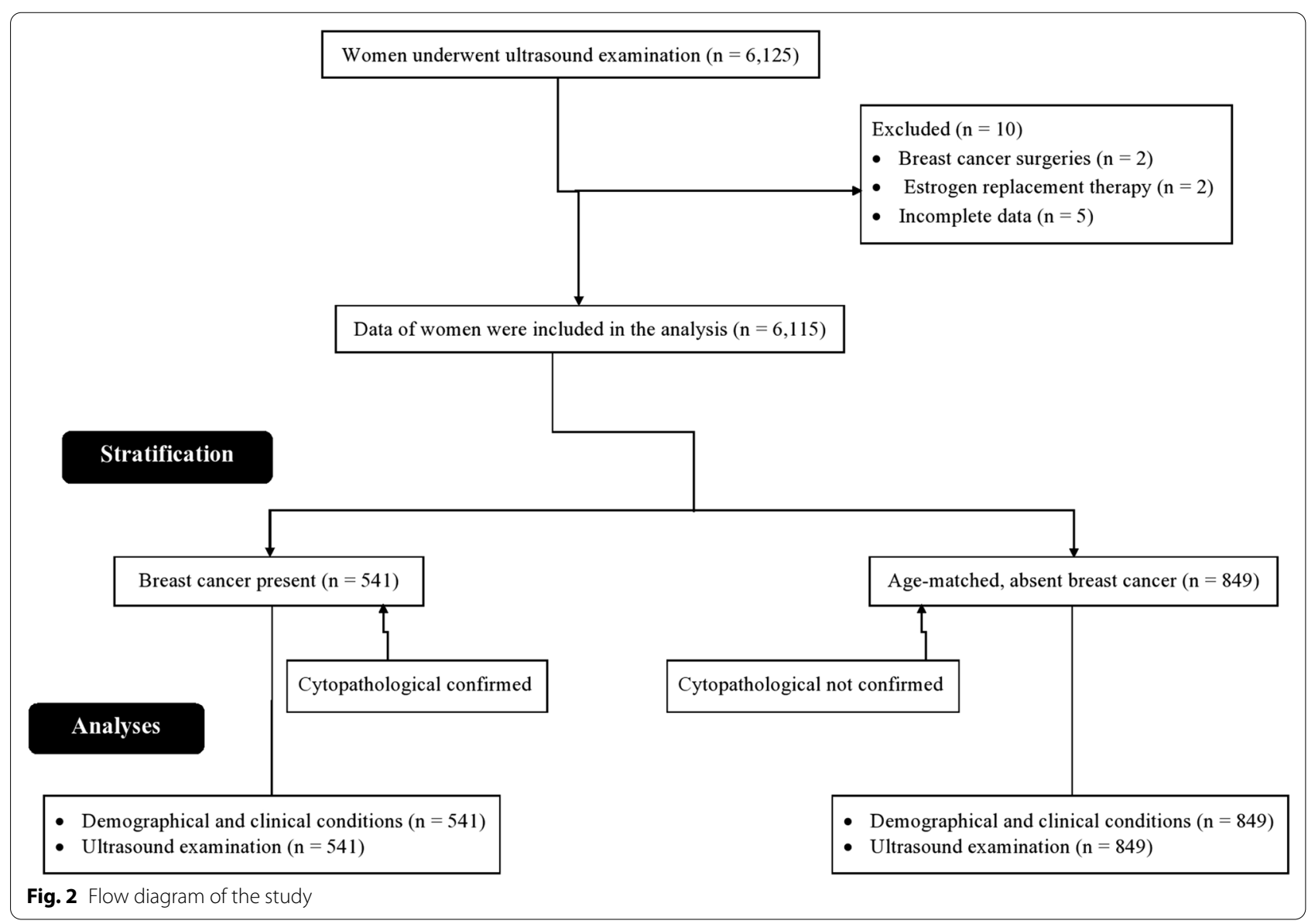


Table 2 Ultrasound examination

\begin{tabular}{|c|c|c|c|c|c|}
\hline \multirow{2}{*}{$\begin{array}{l}\text { Parenchymatous Category } \\
\text { Women }\end{array}$} & \multirow{2}{*}{$\begin{array}{l}\text { Cytopathological confirmed } \\
\text { breast cancer women } \\
541\end{array}$} & \multirow{2}{*}{$\begin{array}{l}\text { Cytopathological not confirmed } \\
\text { breast cancer women } \\
849\end{array}$} & \multicolumn{3}{|c|}{ Comparisons } \\
\hline & & & OR & $95 \% \mathrm{Cl}$ & $p$-value \\
\hline Heterogeneous & $49(9)^{*}$ & $21(2)$ & 3.927 & $2.327-6.627$ & $<0.0001$ \\
\hline Ductal & $29(5)$ & $65(8)$ & 0.683 & $0.435-1.073$ & 0.101 \\
\hline Mixed & $168(31)$ & $502(59)$ & 0.311 & $0.248-0.391$ & $<0.0001$ \\
\hline Fibrous & $295(55)^{*}$ & $261(31)$ & 2.702 & $2.161-3.378$ & $<0.0001$ \\
\hline
\end{tabular}

Variable are demonstrated as frequency (percentages)

Fischer exact test was performed for statistical analyses

All results were considered significant if the $p$-value was less than 0.05 and OR more than 1

OR: Odd ratio,

$\mathrm{Cl}$ : Confidence interval

* Significantly higher value

Table 3 Agreements among sonographer physicians

\begin{tabular}{ll}
\hline Parameters & Values \\
\hline Sonographer physicians & 07 \\
$k$ & 0.591 \\
$95 \% \mathrm{Cl}$ & $0.541-0.721$ \\
\hline
\end{tabular}

$\mathrm{Cl}$ : Confidence interval

$0 \leq k \geq 0.4$ : poor agreement, $0.41 \leq k \geq 0.75$ : fair to good agreement,

$0.76 \leq k>1.0$ : excellent agreement, $k=1.0$ : perfect agreement

parallel with those of an available study [3] and prospective study [13]. The use of three different ultrasound machines, seven sonographer physicians as reader, and the use of manual reading of ultrasound images were responsible for the lower agreement.

There are several limitations of the study, for example, the correlation between ultrasonographic parenchymatous pattern and mammographic parenchymatous pattern were not discussed. The possible justification is that by adding mammography there was an addition of extra cost on women's heads. The retrospective nature of the study and lack of prospective study.

\section{Conclusions}

Breast ultrasound examinations are associated with breast cancer in asymptomatic women. Heterogeneous and fibrous categories of parenchymatous pattern of breast tissues were high-risk ultrasonographic examination categories for breast cancer. The ultrasonographic parenchymatous pattern could be used for screening breast cancer in asymptomatic Chinese women. If questionnaires and ultrasound examinations were performed in the early stage of breast cancer, it is possible to control the spoil of life of women due to breast cancer. The study data have the potential for the basis of breast cancer risk prediction.

\section{Abbreviations \\ ANOVA: Analysis of variance; OR: Odds ratio; Cl: Confidence interval; SD: Standard deviation.}

\section{Acknowledgements}

The authors are thankful for the radiological and non-radiological staff of the First Affiliated Hospital of Fujian Medical University, Fuzhou, Fujian, China and the Fujian Provincial Hospital, Fuzhou, Fujian, China.

\section{Authors' contributions \\ All authors have read and approved the manuscript for publication. ZB and YZ contributed equally to conceptualization, literature review, methodology, resources, and software of the study. SC contributed to investigation, literature review, methodology, resources, and supervision of the study. XC contributed to literature review, methodology, resources, validation, and software of the study. XX contributed to methodology, literature review, resources, data cura- tion, and formal analyses of the study. LW contributed to methodology, litera- ture review, validation, software, and supervision of the study. LC contributed to literature review, methodology, data curation of the study, draft, and edited the manuscript for intellectual content. All authors agree to be accountable for all aspects of work ensuring integrity and accuracy. All authors read and approved the final manuscript.}

\section{Funding}

This study was supported by the Start-up Fund for scientific research of the Fujian Medical University (Grant No: 2017XQ1087).

\section{Availability of data and materials}

The datasets were used and analyzed during the current study available from the corresponding author on reasonable request.

\section{Declarations}

\section{Ethics approval and consent to participate}

The designed protocol (FJPHBCS_1224 dated 23 January 2020) was approved by the Fujian Medical University review board and the Chinese Society of Radiology. The study reporting adheres to the law of China and the V2008 Declarations of Helsinki. Informed consent was not required from women because the study is a retrospective analysis.

\section{Consent to publication}

Informed consent was not required from women regarding publication because the study is a retrospective analysis.

\section{Competing interests}

The authors declare that they have no competing interests. 


\section{Author details}

${ }^{1}$ Department of Ultrasound, First Affiliated Hospital of Fujian Medical University, No 20 Cha zhong Road, Taijiang District, Fuzhou 350000, Fujian, China.

${ }^{2}$ Department of Ultrasound, Provincial Clinical Academy of Fujian Medical

University, Fujian Provincial Hospital, Fuzhou 350001, Fujian, China.

Received: 5 June 2021 Accepted: 23 September 2021

Published online: 19 October 2021

\section{References}

1. Yang Q, Yu X, Zhang W. Health variations among breast-cancer patients from different disease states: Evidence from China. BMC Health Serv Res. 2020;20(1):1-13.

2. Hu Z, Li X, Feng MH, Chu JJ, Xie W. Models for risk assessment and prediction in breast cancer. Chinese J Epidemiol. 2009;30(10):1073-7.

3. Hou XY, Niu HY, Huang XL, Gao Y. Correlation of breast ultrasound classifications with breast cancer in Chinese women. Ultrasound Med Biol. 2016;42(11):2616-21.

4. Wang L, Liu L, Lou Z, Ding L, Guan H, Wang F, Yu L, Xiang Y, Zhou F, Xue F, Yu Z. Risk prediction for breast cancer in Han Chinese women based on a cause-specific Hazard model. BMC Cancer. 2019;19(1):1-8.

5. Evans DG, Howell A. Can the breast screening appointment be used to provide risk assessment and prevention advice? Breast Cancer Res. 2015;17(1):1-9.

6. Boyd NF, Martin LJ, Yaffe MJ, Minkin S. Mammographic density and breast cancer risk: current understanding and future prospects. Breast Cancer Res. 2011:13(6):1-12.

7. Zhu C, Wang L, Du LB, Li J, Zhang J, Dai M, Shi JF. The accuracy of mammography screening for breast cancer: a meta-analysis. Chinese J Epidemiol. 2016;37(9):1296-305.

8. Yaghjyan L, Mahoney MC, Succop P, Wones R, Buckholz J, Pinney SM. Relationship between breast cancer risk factors and mammographic breast density in the Fernald Community Cohort. Br J Cancer. 2012;106(5):996-1003.

9. Bae JM, Kim EH. Breast density and risk of breast cancer in Asian women: A meta-analysis of observational studies. J Prev Med Public Health. 2016;49(6):367-75.
10. An P, Zhong S, Zhang R, Hou X, Xi R, Wang Y. A cross-sectional observational study to compare the role of ultrasound with mammography in women Identified at high risk for breast cancer in a population in China. Med Sci Monit. 2020;26:1-9.

11. Shen S, Zhou Y, Xu Y, Zhang B, Duan X, Huang R, Li B, Shi Y, Shao Z, Liao H, Jiang J, Shen N, Zhang J, Yu C, Jiang H, Li S, Han S, Ma J, Sun Q. A multi-centre randomised trial comparing ultrasound vs mammography for screening breast cancer in high-risk Chinese women. Br J Cancer. 2015;112(6):998-1004.

12. Park CS, Kim SH, Jung NY, Choi JJ, Kang BJ, Jung HS. Interobserver variability of ultrasound elastography and the ultrasound BI-RADS lexicon of breast lesions. Breast Cancer. 2015;22(2):153-60.

13. Kim WH, Lee SH, Chang JM, Cho N, Moon WK. Background echotexture classification in breast ultrasound: Inter-observer agreement study. Acta Radiol. 2017;58(12):1427-33.

14. Li H, Giger ML, Lan L, Janardanan J, Sennett CA. Comparative analysis of image-based phenotypes of mammographic density and parenchymal patterns in distinguishing between BRCA1/2 cases, unilateral cancer cases, and controls. J Med Imaging. 2014;1(3):1-10.

15. Chen $\mathrm{Q}$ Xia J, Zhang J. Identify the triple-negative and non-triple-negative breast cancer by using texture features of medicale ultrasonic image: a STROBE-compliant study. Medicine. 2021;100(22):1-6.

16. Lokate M, Peeters PH, Peelen LM, Haars G, Veldhuis WB, van Gils CH. Mammographic density and breast cancer risk: the role of the fat surrounding the fibroglandular tissue. Breast Cancer Res. 2011;13(5):1-8.

17. Ghosh K, Vachon CM, Pankratz VS, Vierkant RA, Anderson SS, Brandt KR, Visscher DW, Reynolds C, Frost MH, Hartmann LC. Independent association of lobular involution and mammographic breast density with breast cancer risk. J Natl Cancer Inst. 2010;102(22):1716-23.

\section{Publisher's Note}

Springer Nature remains neutral with regard to jurisdictional claims in published maps and institutional affiliations.
Ready to submit your research? Choose BMC and benefit from

- fast, convenient online submission

- thorough peer review by experienced researchers in your field

- rapid publication on acceptance

- support for research data, including large and complex data types

- gold Open Access which fosters wider collaboration and increased citations

- maximum visibility for your research: over 100M website views per year

At BMC, research is always in progress.

Learn more biomedcentral.com/submissions 